\title{
Integration Trend of Digitalization of Teachers' Labor in the Practice of Russian Universities
}

\author{
Maria Zakharova ${ }^{1, *}$, and Maksim Voronin ${ }^{2,3}$ \\ ${ }^{1}$ Kutafin Moscow State Law University (MSAL), 123001 Moscow, Russia \\ ${ }^{2}$ Lomonosov Moscow State University,119991 Moscow, Russia \\ ${ }^{3}$ Kazan Federal University,420008 Kazan, Russia
}

\begin{abstract}
The article examines the features of the organization of the educational process in the context of digitalization, analyzes the integration tendency of teachers' work in the practice of Russian universities, provides a comparative analysis of the practice of the Open University. This paper analyzes the educational experience that has developed in the process of emergency delivery of educational content to students during a pandemic. The models of mixed, purely distance and duplicate education are analyzed. The article substantiates the idea that there is a need for the formation of criteria for the quality of education online, and, therefore, the criteria for the quality of the organization of the educational process, including the work of teachers, are changing. This paper outlines some steps that are being taken by Russian universities in the field of researching trends related to improving the digital environment as a whole, regardless of the pandemic and other factors.
\end{abstract}

\section{Introduction}

A teacher and a student have always been and are not only a public union for the successive transfer of knowledge, but also a wider ideological institution, where the intellectual component is just as important as the emotional and value ones; and where the roles sometimes change: "by teaching we learn ourselves," Seneca used to say.

The ancient intellectual schools, the Plato's Academy and the Aristotle Lyceum, became excellent examples of scientific schools, a club of like-minded people who, in their joint scientific work, comprehended the law of nature and the mysteries of the human spirit. Over a long history, universities have accumulated huge baggage not only of intellectual treasures as such, but also methodological platforms for transferring accumulated knowledge from one generation to another.

Until recently, live communication between teachers and students became the main form of transferring the accumulated scientific experience. The launch of the Open University project became a turning point towards the introduction of distance learning in universities around the world.

\footnotetext{
*Corresponding author: avis_777@mail.ru
} 


\section{Materials and methods}

In the process of preparing the article, both general and special methods of cognition were applied. Formulation of doctrinal approaches to the problems presented in the paper is impossible without comparative analysis carried out within the framework of interdisciplinary, intersectoral (comparative analysis of approaches), transboundary, and chronological approaches.

\section{Results and discussion}

One of the pilot projects in this regard should be considered the creation of the Open University of Great Britain back in 1975. Over the years, the Open University of Great Britain has become a world leader in distance learning and seeks to play a leading role in the spread of higher and postgraduate education over a vast area, from Dublin to Petropavlovsk-Kamchatsky. Now, in 400 educational centers teaching according to the programs of the university, more than 200 thousand people study annually.

Experience of the Open University. Nowadays, the "open university" institution is becoming a common practice not only for European and Northern European educational institutions, but also for developing economies. A typical example in this case is a largescale project launched in 1985 in India at the initiative of the country's government. The Open University is named after Indira Gandhi, and today it unites more than 4 million people in its virtual walls!

Penetrating into all corners of the modern political, legal and economic map of the world, the Open University institution becomes the basis for the integration practice of states in this matter. Thus, to a certain extent, the continuation of the "open university" structure should be considered the global network of mega-universities: Global MegaUniversity Net - GMUNET. The term "mega-university" was first introduced by J. Daniel in his famous book on mega-universities. The introduction of this new category of higher education institutions by J. Daniel explains the obvious influence of a large-scale factor on the problems faced by a distance university. The formal sign of a mega-university is the number of students not less than 100 thousand people. However, the concept itself is much broader, it includes a number of criteria, of which the main ones are: the use of distance learning technologies based on ICT; openness, accessibility of education; guarantee of high-quality education while simultaneously focusing on mass education; effective student support. In 2003, an extremely important event that influenced the further strategy for the development of distance education in the world took place in Shanghai (China), the First World Summit of the leaders of the world's mega-universities, at which a declaration was adopted on the creation of a global network of mega-universities (Global Mega-University Net - GMUNET).

Distance work of university teachers is becoming one of the forms of so-called atypical employment. A special term has been introduced in the European legal field, ICT-based mobile work, i.e. work related to the use of information and communication technologies, when employees are not tied to a specific location of the employer and can work from anywhere. This variant of the performance of the work function is referred to in the report of the Eurofond as one of the nine newest atypical forms of employment in the modern world.

According to statistics, the use of the institution of distance work is uneven on the legal map of the world. For instance, in the United States in 2017-2018, one in four workers did at least part of their work at home, and in $2019,13 \%$ of workers did work at home all day at least once every two weeks, and $3.6 \%$ of workers performed work completely outside the employer's location for at least half of their working days. In Russia, for comparison, for 
2019, according to Rosstat, out of 67.1 million people employed in the country, only 30 thousand people worked under "distance" labor contracts, i.e. there were more than 2,200 stationary workers per one remote worker.

As experts in the field of labor law note, together with a noticeable increase in the comfort of the work function (primarily for employees who do not spend time and money on the way from home to work), distance work generates a certain range of legal issues that are equally relevant as in the Western and the Eastern Hemisphere legal map of the world. One of the main problems is the problem of distinguishing between rest time and work time. If a typical worker of the industrial era in most cases could afford, leaving work, to leave all the problems associated with work "at the office" and switch his or her attention to family and leisure, in modern society, a typical office worker is increasingly "bringing home" all work problems, continuing (sometimes at any time of the day or night) to answer work calls and emails. This leads to the fact that a person does not fully recover his or her strength at home, does not perceive home and rest time as a place and time free from work. As a result, the problem of emotional burnout and stress in the workplace is becoming more acute. In 2016, to celebrate World Day for Safety and Health at Work, the ILO issued a policy paper on workplace stress, which has already come to be perceived as a fundamental threat to workers' health.

Apologists for the "open university" structure argue that, compared to a traditional (mass) university, the Open (virtual) university has shown itself to be more effective in solving such problems as:

- development of a theory to improve the level of knowledge (research),

- adjustment of intellectual, diagnostic methods and planning methods, making them more adapted to the constant changes taking place in the world;

- development by individuals of their own powers;

- maximum compliance with the goals of educational institutions, the needs of sociocultural and economic development;

- advancement of a worthy supply for the demand for intellectual resources from the production forces.

We can partly agree with the statements presented, presupposing the idea that an open university is, first of all, an embodied idea about the accessibility of education, about realizing the potential of young people in the intellectual sphere in the case when, for a number of reasons (primarily of an economic and geographical nature), traditional educational forms are not available. But in the pair "open university - traditional university", the former variant of the educational process is an exception, while the latter is the rule and the leading line. This state of affairs persisted until recently in the world educational space. The dividing stone was set (as well as in many other social practices and aspects of human life) in connection with the global epidemiological situation on a global scale caused by the spread of a new coronavirus infection. Various universities around the world have begun to close their centuries-old oak doors for classrooms.

The need for urgent delivery of online content has arisen as a result of the pandemic. In this regard, Russian universities are implementing global trends in the digitalization of teachers' work, and just like their partners in the university community today are in a difficult situation regarding the peculiarities of the functioning of universities in the context of the global epidemiological crisis.

In March 2020, Russian universities faced the need for urgent delivery of educational content. The universities were not ready to switch over to the distance learning format overnight. However, the academic year 2019-2020 was not over yet, and the need to continue training highlighted the need for urgent delivery of online content. This problem has forced all universities to transform online learning. Having said that, it is important to 
understand that, in general, the systematic development of online education tools became impossible, it had to be accelerated.

Over the years of development of online education, a number of factors have developed that determined the popularity of online courses: 1) increasing the subjectivity of students (their role in the learning process); 2) the need for constant knowledge acquisition, lifelong learning; 3) online courses (especially of large global platforms) began to be recognized by employers, including global companies; 4) changes in the labor market and the need for rapid training, retraining of employees; 5) availability (territorial, financial, etc.) and many more.

In the context of an acute pandemic, the previously relevant reasons for the development of online courses have lost their former significance. This does not mean that these factors in the popularity of online courses are not at all significant, just in conditions when people do not have an alternative between online learning and full-time education, there is no need to convince anyone of the need for digital education.

Even before, Russian universities, in general, developed online learning, the main indicators of the progressive movement of which were MOOCs, the number of courses on captive (internal university) platforms. We wondered if there are more MOOCs in the pandemic or not? Let's give an example based on legal education. Comparing the statistics for 2019 with the number of MOOCs in jurisprudence in 2020, we can conclude that during the pandemic there were slightly more MOOCs than in the previous year: the growth was observed at St. Petersburg State University (SPbSU) - by 18 MOOCs more; O.E. Kutafin Moscow State Law Academy - by MOOCs 19 more (8 paid, 11 free); MSIIR - by 6 MOOCs more; European University at St. Petersburg (EUSPB) - by 3 MOOCs more; Far Eastern Federal University (FEFU) - by 2 MOOCs more; ITMO University - by 1 MOOC more; Peter the Great St. Petersburg Polytechnic University (SPbPU) - by 1 MOOC more; Financial University under the Government of the Russian Federation - by 1 MOOC more. The data are given from the practical analysis of the web-sites of the above organizations in 2019 and 2020 by the authors of the article. The conclusion that can be made is that not all universities have sought to build up massive open online courses during the pandemic, because they focused on solving the issue of delivering educational content in a nonstandard environment. The experience of the growth in the number of internal online courses at Russian universities in 2020 has yet to be comprehended. However, it is necessary to take into account the existing approaches to online learning in a pandemic.

As a result of the need for the urgent delivery of educational content in Russia, there were mainly three training models in the period from September to December 2020. Here is their description A)Purely online/distance learning, when all types of interaction between students, teacher and management personnel take place remotely using electronic communications and programs such as Zoom, Skype, etc. This training model has been applied, e.g., at the Russian State University of Justice practically since the beginning of the pandemic.

This model is radically opposite to the offline learning model and, as a result, combines all the advantages of online education (no time wasted on the way to the place of learning, digital access to all necessary resources, etc.) with all its shortcomings (lack of emotional connection between student and teacher, interest in the subject). Its main drawback, from our point of view, is the absence of a mechanism for any face-to-face interaction with the teacher, as well as the complete inapplicability of the criteria for the quality of the organization of full-time education, which will be discussed further.

B)Mixed learning, when online classes are alternated with classic classroom sessions. This model was used at the Faculty of Law of the M.V. Lomonosov Moscow State University until October 19, 2020, after which the Faculty of Law was transferred to full distance learning due to the deterioration of the epidemiological situation. The format of the 
training depended on the specific subject, some disciplines were taught in person, while others were conducted online. Also, this training model was used at the O.E. Kutafin Moscow State Law Academy, where the training format alternated by weeks: one week classes were held in full-time form, next week - distantly. The advantage of this model is a certain approximation of the system of criteria for the quality of the organization of online education to the quality of offline education, an opportunity for the teacher and student to find optimal educational solutions, to understand which topics in the subject in which format is better to study. But it also has some disadvantages: when alternating classes by week (O.E. Kutafin Moscow State Law Academy) a certain "habit" to the form is not developed (one week is not enough), there may be difficulties in organizing the schedule and others; under the model, when offline (only practical lessons) interest in lectures may decrease, students have no "feeling" that they are studying in a large class, course, communication takes place within the academic group, there is no live contact with lecturers.

C) Overlapping teaching, which involves conducting the lesson in two forms at once: some of the students, together with the teacher, are in the classroom, while the rest are taught using electronic means. The choice of the format for attending the seminar was given to each student at his or her own discretion. This learning model was applied, e.g., at the Faculty of Economics of the M.V. Lomonosov Moscow State University, at the Kazan Federal University and others. The advantage of this model is that it provides an opportunity to receive a full-fledged high-quality education for those students who attend absolutely all classes offline. However, in a pandemic, not all students have the opportunity to attend classes in person. The same students who, for certain reasons, can attend the class exclusively online, are given less teaching attention. They have a much lower emotional connection with the teacher and are less subject to teacher control. As a result, the level of involvement of such students and the quality of assimilation of the provided material decreases.

In a pandemic, the conversation about the quality criteria for organizing online education is gaining momentum. Legal scholars dealing with this problem are seriously thinking about these issues. It is important to distinguish between the criteria for the quality of online education and the criteria for the quality of the organization of online education. The conversation about the first has yet to be held, and the criteria to be comprehended, since, from our point of view, it is possible to analyze the quality of education itself only when a graduate who has received such an education begins to work in the real world, applies the education received. However, it should be noted that the quality of online education directly depends on the quality of the "educational process-online", since it is this that affects the assimilation of the acquired knowledge. A huge amount of information can be transmitted through online educational tools, but not all of this amount of information "goes" into the knowledge of students. Thus, in addition to the criteria for online education, there is an urgent need to determine the criteria for the online learning process.

Currently, it is not possible to objectively isolate single key quality criteria due to the fact that the online learning institute is just beginning its full-fledged formation, but today active research work is already underway to understand the problems of online education. Scientists and educators are looking for ways and approaches by which it is possible to eliminate the disadvantages of online education. Thus, in 2020 at the Faculty of Law of M.V. Lomonosov Moscow State University, the scientific and educational center "Digital Educational Environment" was opened. The center and its partners have developed an approach that takes into account the evolution of time-tested criteria for the quality of legal education in the context of digitalization. The concept and approach to solving the problem of creating an integral digital educational environment for lawyers, developed by the REC "Digital Educational Environment" of the Faculty of Law of M.V. Lomonosov Moscow 
State University, (see the article in more detail: Creation of a digital educational environment for a law school (based on materials from the Faculty of Law of M.V. Lomonosov Moscow State University)) were approved by the Russian Academy of Education as one of the possible approaches to solving the problem (Resolution of the Bureau of the Professional Education Department of the Russian Academy of Education dated November 27, 2020).

It is important that this concept can have a wide range of applications, not only in the training of lawyers. It takes into account such criteria of the quality of the organization of the learning process as: teaching staff; educational and methodological support; material and technical and technological support; integration of education and science; integration of education and practice; integration of national and world education; availability; continuity.

\section{Conclusions}

Thus, two trends in the integration development of digitalization of teachers' labor can be noted: a) the first is associated with the improvement of the digital environment as a whole, regardless of the pandemic and other factors - the economy and the world as a whole is becoming digital, in these conditions it is important to create an effective digital educational environment, to research and develop a system of criteria for the quality of online education and the quality of the organization of the online learning process; $b$ ) the second is associated with a pandemic and the need for urgent delivery of educational content, from our point of view, this acts as a catalyst for the first trend.

\section{Acknowledgments}

The study was performed based on a grant from the Russian Science Foundation (project No. 19-1800517).

\section{References}

1. Daniel John S., Technology Strategies for Higher Education (1996)

2. Eurofound, New forms of employment. Luxembourg: Publications Office of the European Union, 7 (2015)

3. S.W.Pabilonia, V. Vernon, Telework and Time Use in the United States, May (2020) https://www.researchgate.net/

4. M.V.Voronin, M.V.Zakharova,IUSH, InstitucionUniversitaria Salazar Y Herrera, Medellin-Colombia, 1, 1322 (2017)

5. M.V. Voronin, M.V. Zakharova,Journal of Critical Reviews,7(10), 539 (2020)

6. M.V.Voronin, M.V.Zakharova,Bulletin of Perm University Legal Sciences.,1(43), 19 (2019)

7. A.Briganti, I. P.Khominich, Bulletin of the REA,3 (2011)

8. A.K.Golichenkov, M.V.Voronin, N.A.Esipov, Bulletin of Moscow University, 11(2), 3 (2020)

9. A.V. Klochkova,Quality of legal education, Dean and teacher handbook, 351 (2020)

10. N.L.Lyutov, Journal of Russian Law,12(2020)

11. ILO, Workplace stress: a collective challenge. Decent Work Technical Support Unit and ILO Office for Eastern Europe and Central Asia (2016) 
12. O. M.Slesarchuk,News of the A.I. Gerzen Russian State Pedagogical University, 96, 108 (2009)

13. N.V.Slesarchuk, Urgent problems of Russian law, 8, 108 (2019)

14. A.Shuinov, Higher education in Russia, 7, 42 (2005) 